\title{
Fotoperformance como Estratégia Artística: Isolamento Social Voluntário e Reinvenção da Casa
}

\author{
Photoperformance as an Artistic Strategy: Voluntary \\ Social Isolation and Home Reinvention
}

Fotoperformance como una Estrategia Artística: Aislamiento Social Voluntario y Reinvención del Hogar

\begin{abstract}
(iD)
Tatiana dos Santos Duarte

Universidade Federal de Pelotas

(iD)

Thiago Heinemann Rodeghiero

Universidade Federal de Pelotas
\end{abstract}

Data de submissão: 18/06/2020

Data de aprovação: 10/10/2020

A arte contemporânea é afetada pela vida. Em meio a solitude imposta pela covid-19, produzimos releituras da história da arte, onde mulheres artistas são protagonistas. Ao abraçar o contexto do isolamento social voluntário, mantemos a saúde mental e emocional com processos artísticos que se conectam com outras pessoas, reinventando a casa e cuidando de si (FOUCAULT, 2017).

Essas releituras são uma fotoperformance deste momento, “conferindo-lhe autonomia discursiva” (VINHOSA, 2014, p. 2882). Foram feitas duas imagens por dia, transformando-as em poesia. Em todas as etapas (a casa como estratégia de expressão, a pesquisa dos artistas e a montagem da fotoperformance) encontra no corpo gestos de potência (GIL, 2001). 
Fotoperformance como Estratégia Artística: Isolamento Social Voluntário e Reinvenção da Casa

Tatiana dos Santos Duarte • Thiago Heinemann Rodeghiero

Os trabalhos dessas mulheres, pelos quais nós nos ancoramos, são esquecidos e desconhecidos pelo grande público: a história da arte priorizou artistas homens. Assim, compomos imagens que colocam a mulher como protagonista.

O meio doméstico possibilitou uma fabulação ao criar outros lugares para desenfadar-se: uma diversão-brincante à serviço da saúde. Ao juntar objetos e gestos, faz-se uma relação entre arte e vida, colocando a casa à viajar e habitar novos lugares e territórios.

Nosso processo foi partilhado nas redes sociais virtuais (facebook, instagram, youtube e twitter) em meio às fake news, discursos de ódio, ataque a ciência e abandono da saúde pública. Logo, as releituras encontram uma fuga e dão um alívio ao stress causado pela necropolítica (MBEMBE, 2018) geradora de desconforto. Não é criar uma fake arte, é lutar contra o esquecimento dessas mulheres artistas pois, ao reinventarmos seus trabalhos, damos lufadas de vida a esta negligenciada fatia da história da arte. A janela virtual da casa é aberta para alcançar o mundo num aglomerado sensível, buscando uma sensação de presença neste contexto pandêmico

As fake news descredibilizam a ciência, fazendo que discursos fáceis e tendenciosos sejam aceitos (um novo normal). Elas criam um ambiente propício ao embrutecimento e ao fascismo, pois surgem sem referência, sem diálogo e sem dono, atordoado quem as aceita como verdade. As releituras dão força a cientificidade pois, ao não pretendem ser um substituto ou substituir trabalho referido, trazer as devidas referências e criar uma nova possibilidade de fruição da arte, impulsionam o pensamento a novos sentidos e leituras de mundo. Portanto, mais do que um exercício contra o negacionismo científico, as releituras dão aos espectadores uma possibilidade de arte que se prolifera em meio a vida, dando as devidas fonte para que estes possam encontrar novas formas sensíveis e conhecer um pouco deste recorte da história da arte. 
Fotoperformance como Estratégia Artística: Isolamento Social Voluntário e Reinvenção da Casa

Tatiana dos Santos Duarte • Thiago Heinemann Rodeghiero

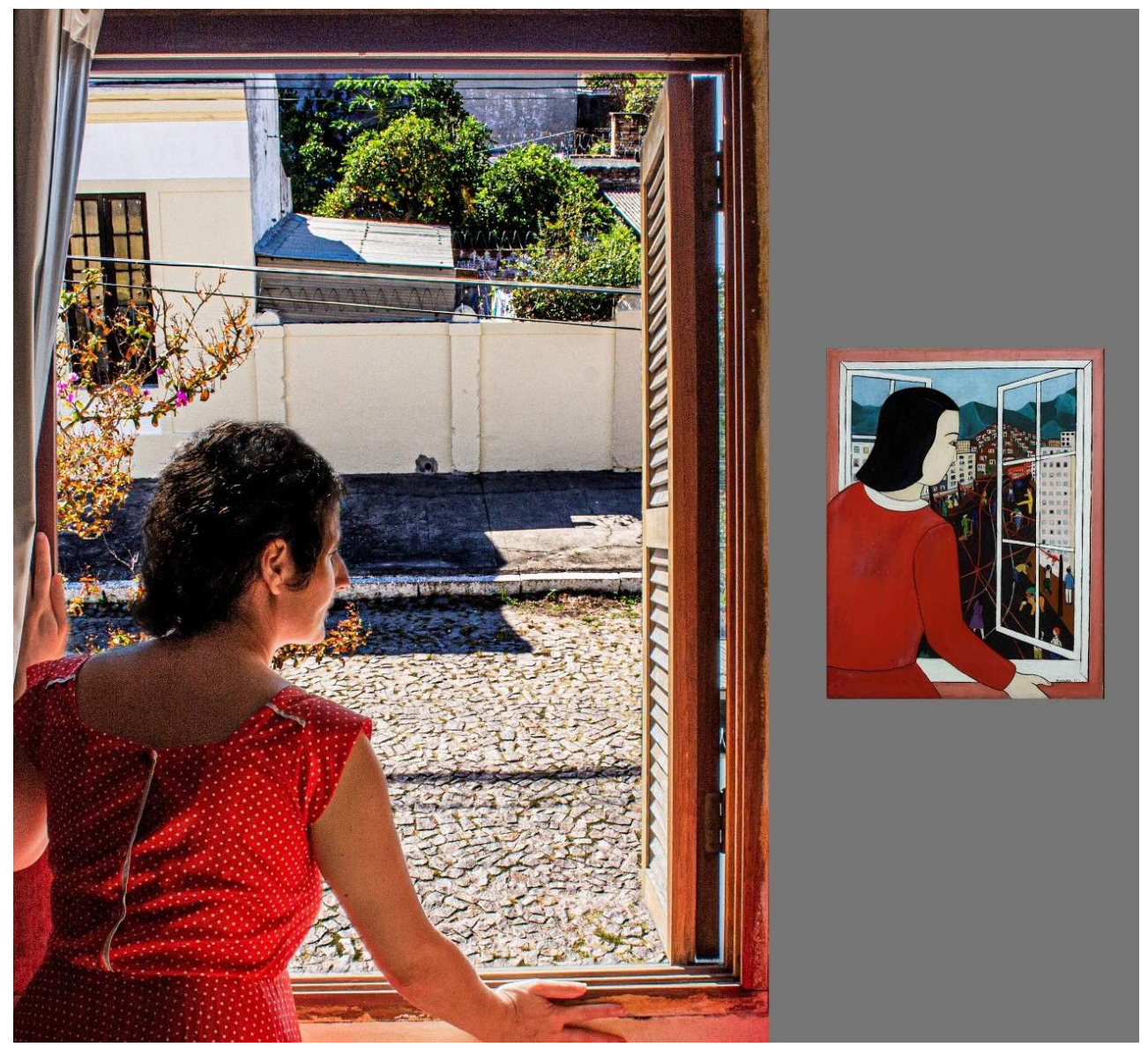

Imagem 1 Janela para o mundo, uma releitura de Djanira da Motta e Silva - Moça olhando na janela (coleção particular de João Sattamini). Foto de Tatiana Duarte (2020).

Fonte: Arquivo Pessoal, 2020.

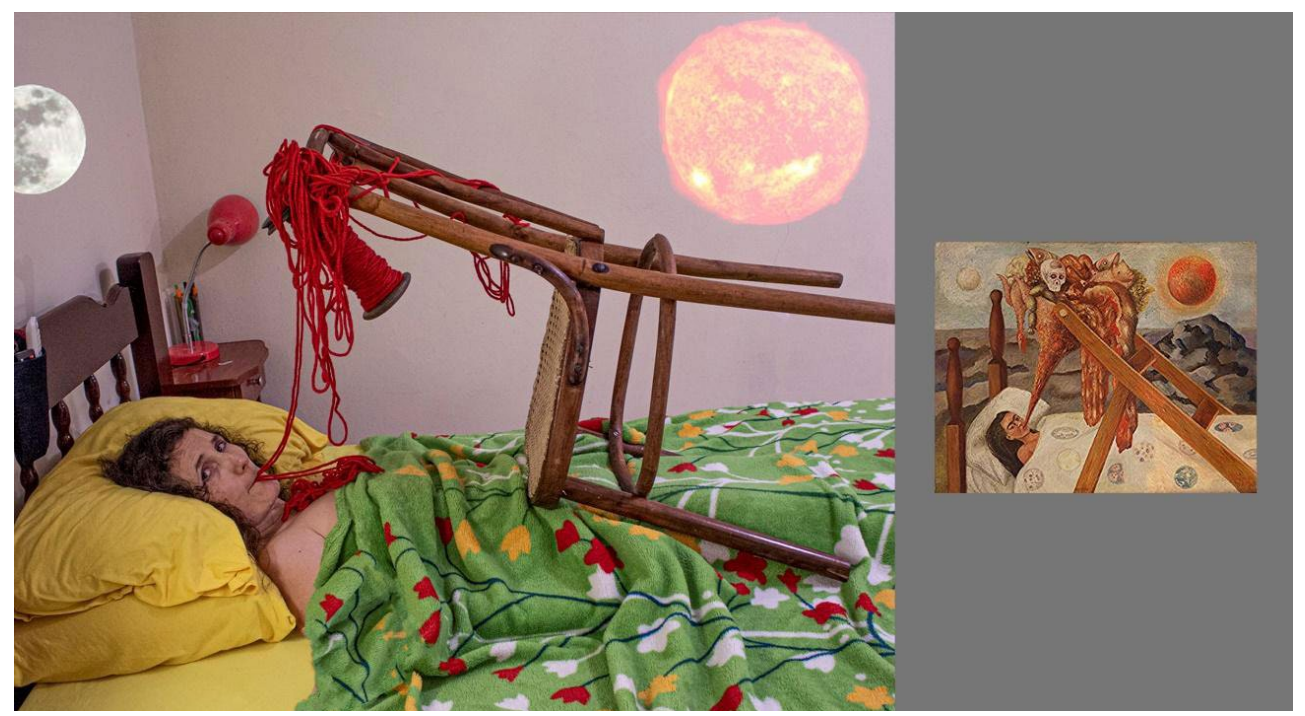

Imagem 3 Isolamento, uma releitura de Frida Kahlo - Sem esperança (Coleção particular de Dolores Olmedo Patiño). Foto de Tatiana Duarte.

Fonte: Arquivo Pessoal, 2020. 
Fotoperformance como Estratégia Artística: Isolamento Social Voluntário e Reinvenção da Casa

Tatiana dos Santos Duarte • Thiago Heinemann Rodeghiero

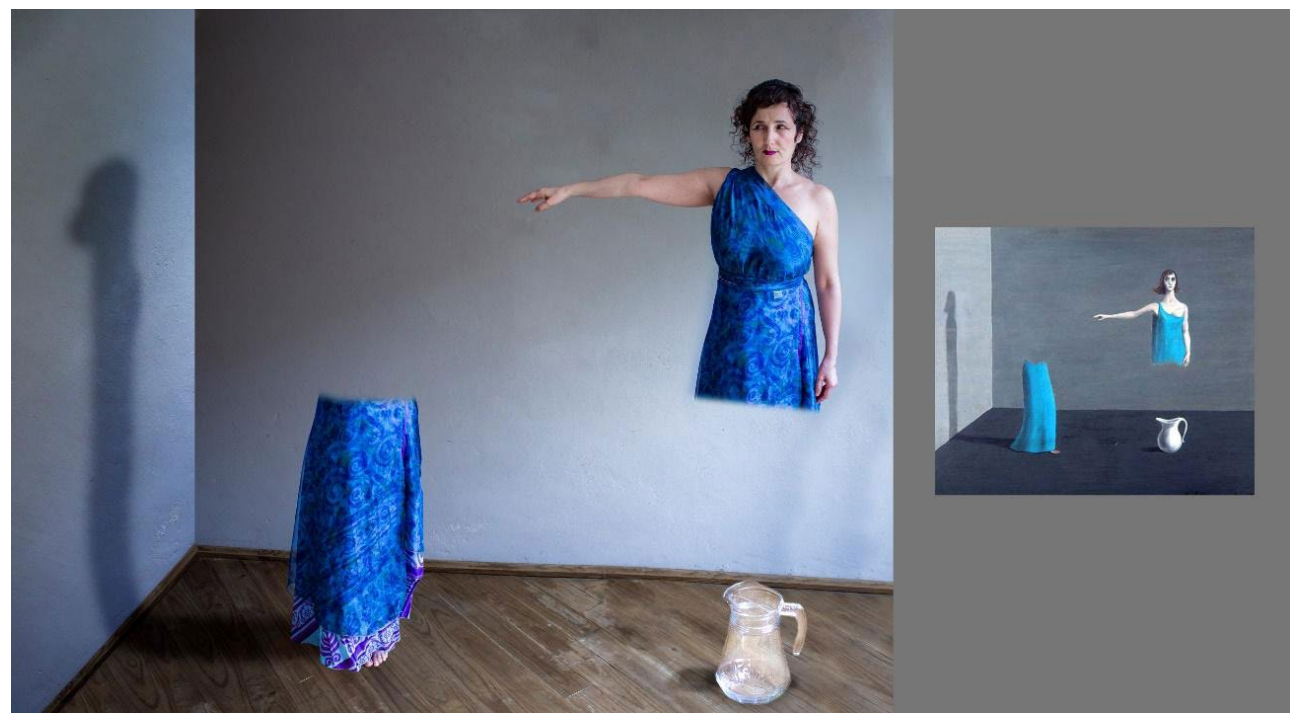

Imagem 4 Corpo Virtual, uma releitura de Gertrude Abercrombie - Desdobramento de personalidade (coleção particular). Foto de Tatiana Duarte.

4 Fonte: Arquivo Pessoal, 2020.

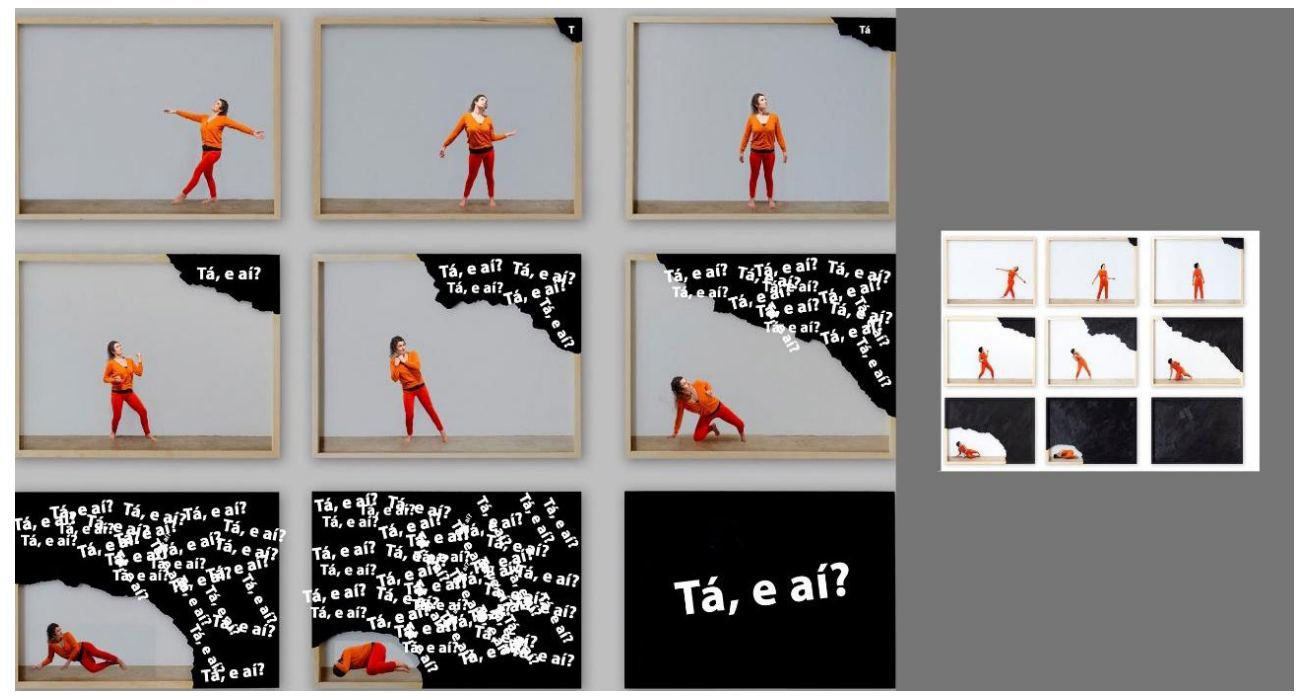

Imagem 5 Tá, e aí?, uma releitura de Celina Portella - Fotonovela da opressão (Zipper Galeria). Foto de Tatiana Duarte.

Fonte: Arquivo Pessoal, 2020. 
Fotoperformance como Estratégia Artística: Isolamento Social Voluntário e Reinvenção da Casa

Tatiana dos Santos Duarte • Thiago Heinemann Rodeghiero

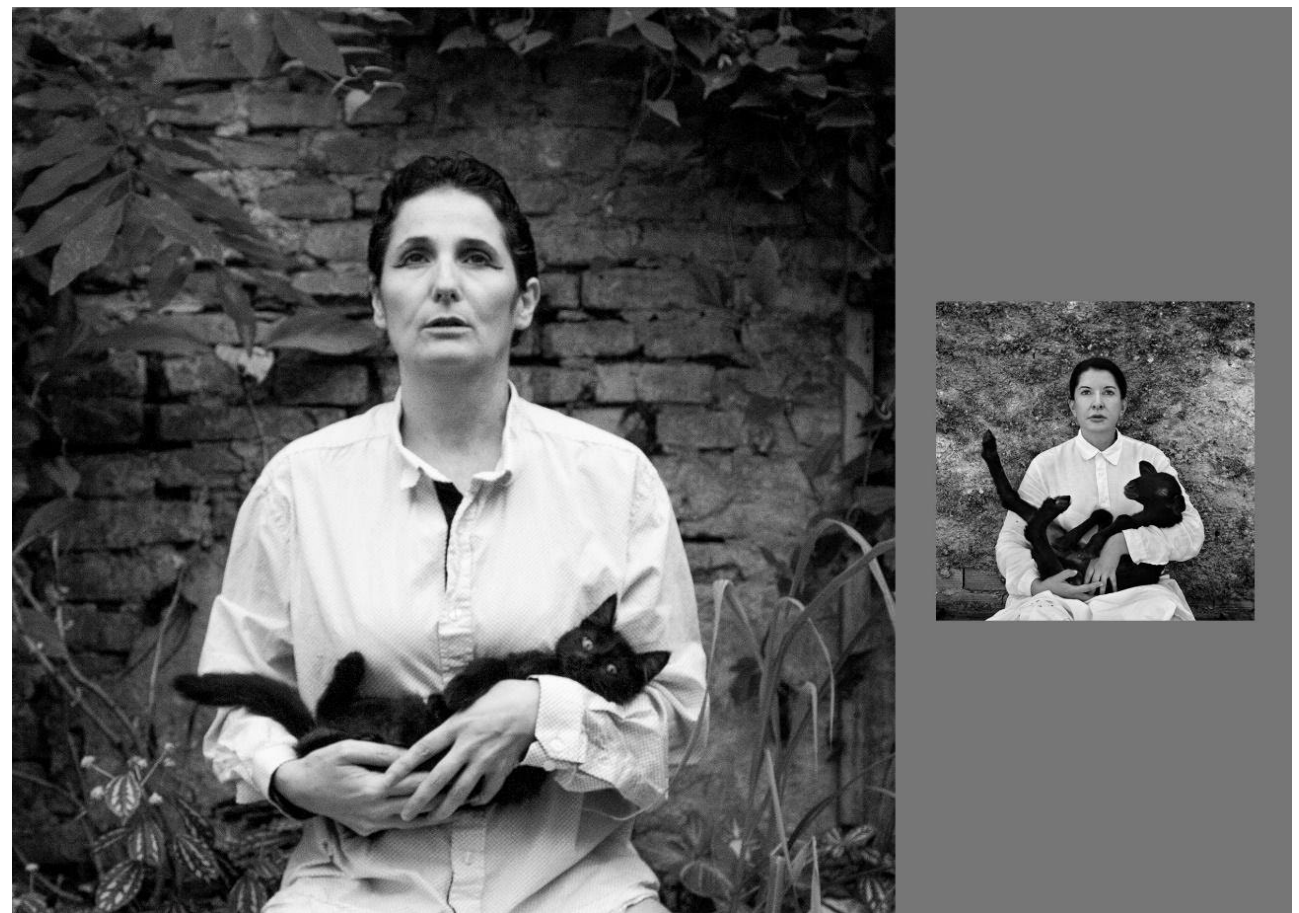

Imagem 6 No pátio, uma releitura de Marina Abramovic - Retrato Com Cordeiro Negro

5

(Galeria Wilde). Foto de Tatiana Duarte.

Fonte: Arquivo Pessoal, 2020.

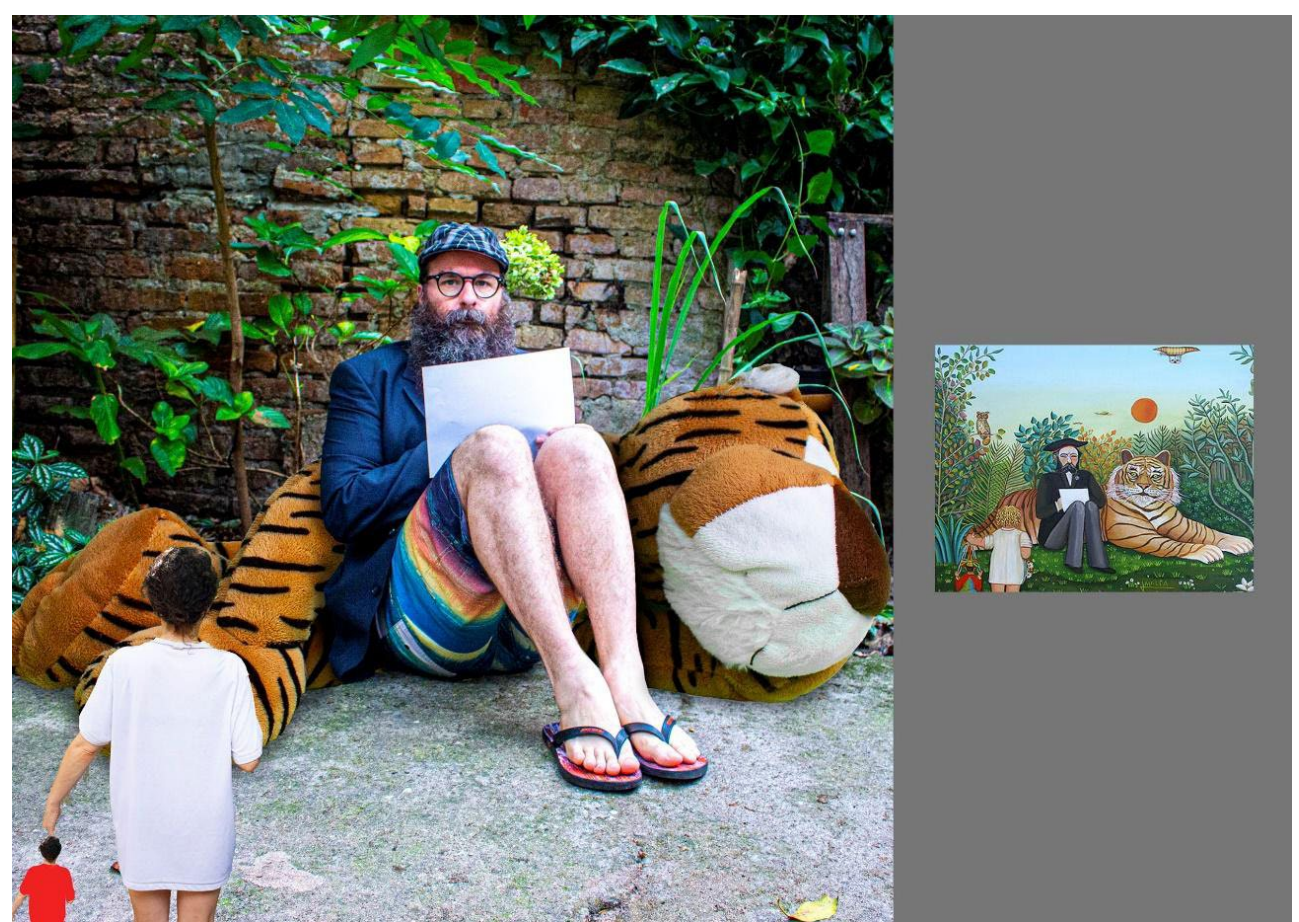

Imagem 7 Releitura de Amalia Fernández de Córdoba (coleção particular). Foto de Thiago Rodeghiero. Fonte: Arquivo Pessoal, 2020. 
Fotoperformance como Estratégia Artística: Isolamento Social Voluntário e Reinvenção da Casa

Tatiana dos Santos Duarte • Thiago Heinemann Rodeghiero

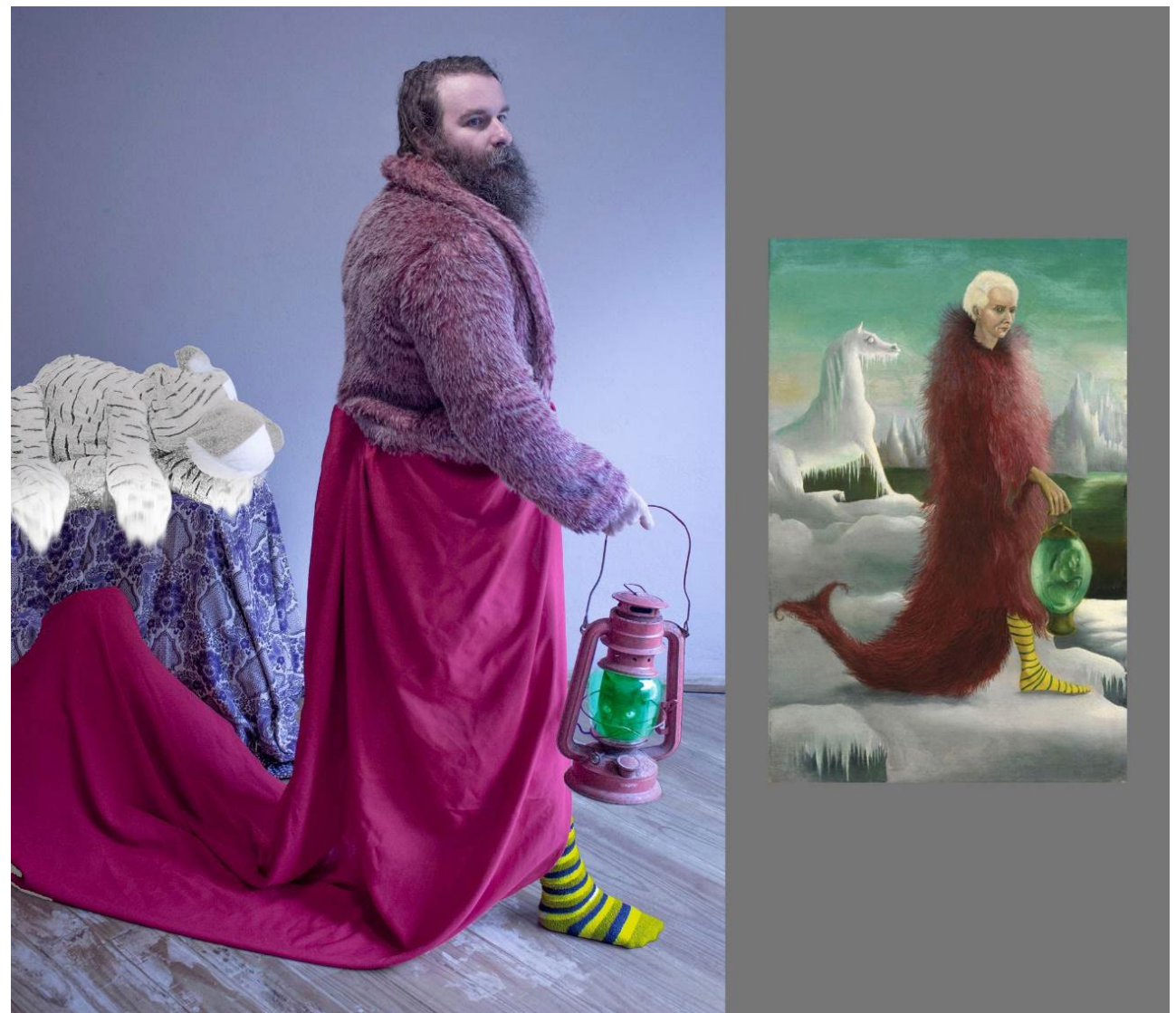

6

Imagem 8 Releitura de Leonora Carrington - Retrato de Max Ernst (coleção particular).

Foto de Thiago Rodeghiero.

Fonte: Arquivo Pessoal, 2020

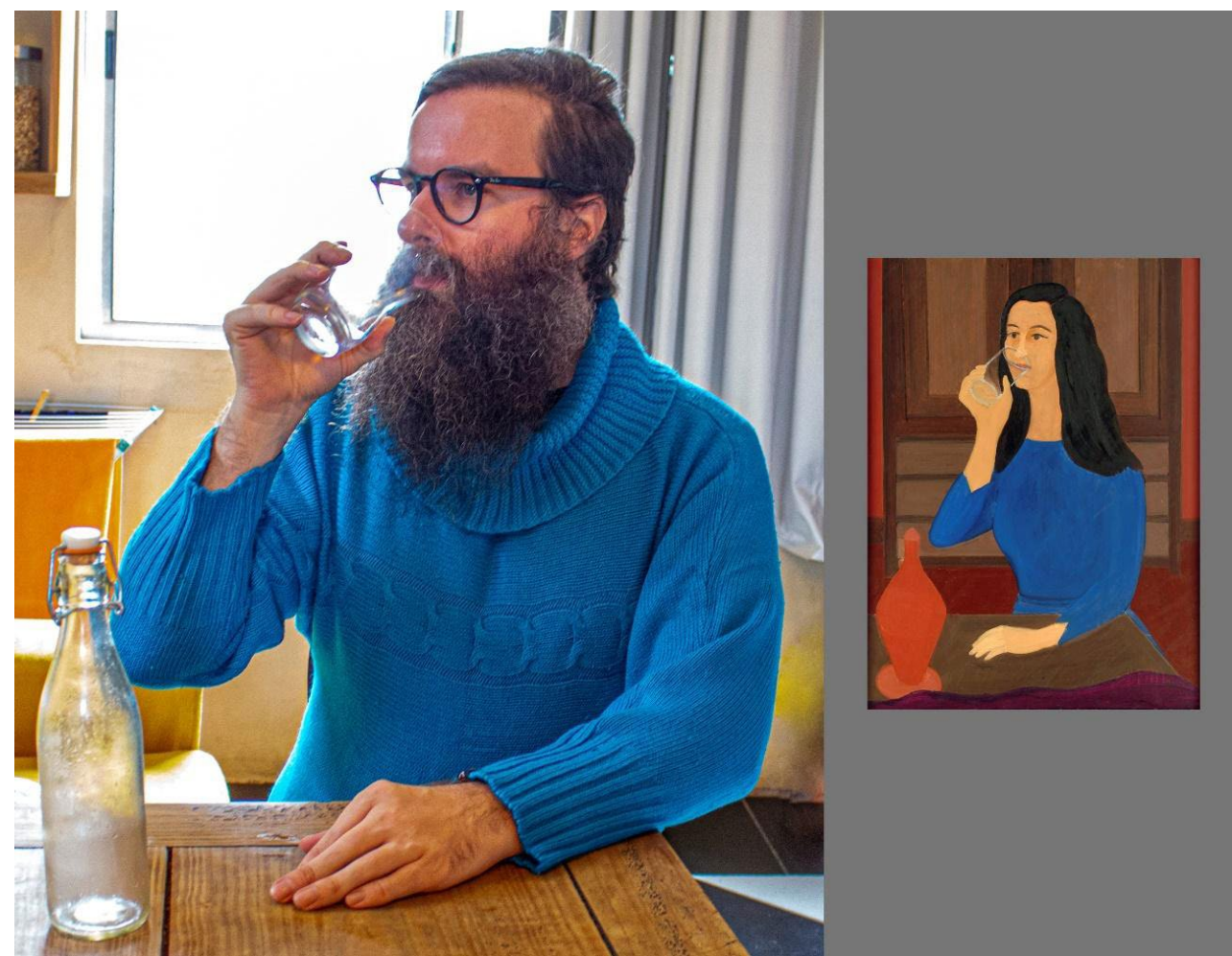

Imagem 9 Releitura de Djanira da Motta e Silva - Retrato (coleção particular). Foto de Thiago Rodeghiero. Fonte: Arquivo Pessoal, 2020 
Fotoperformance como Estratégia Artística: Isolamento Social Voluntário e Reinvenção da Casa

Tatiana dos Santos Duarte • Thiago Heinemann Rodeghiero

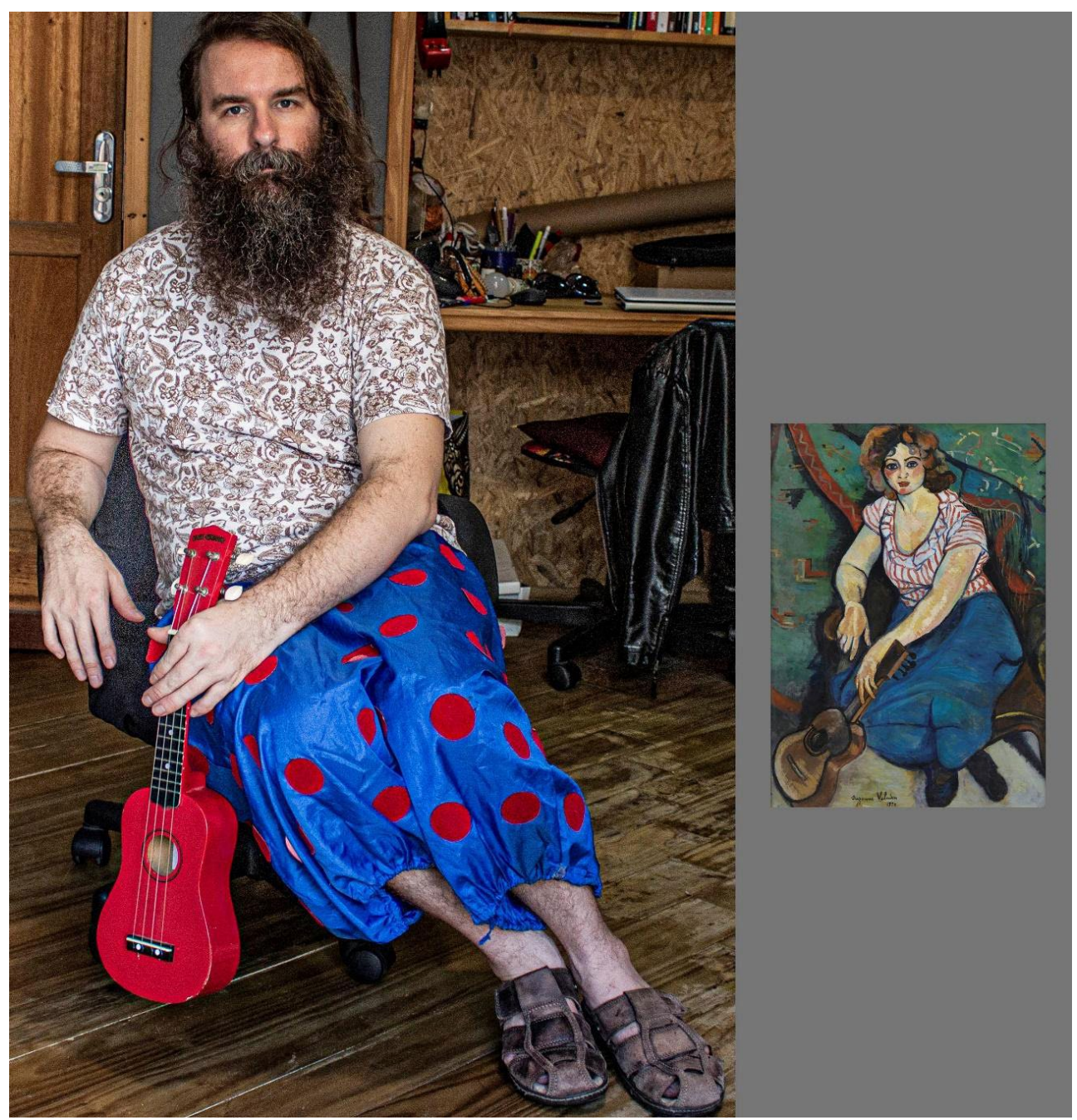

Imagem 10 Releitura de Suzanne Valadon - A sala azul (coleção particular). Foto de Thiago Rodeghiero. Fonte: Arquivo Pessoal, 2020.

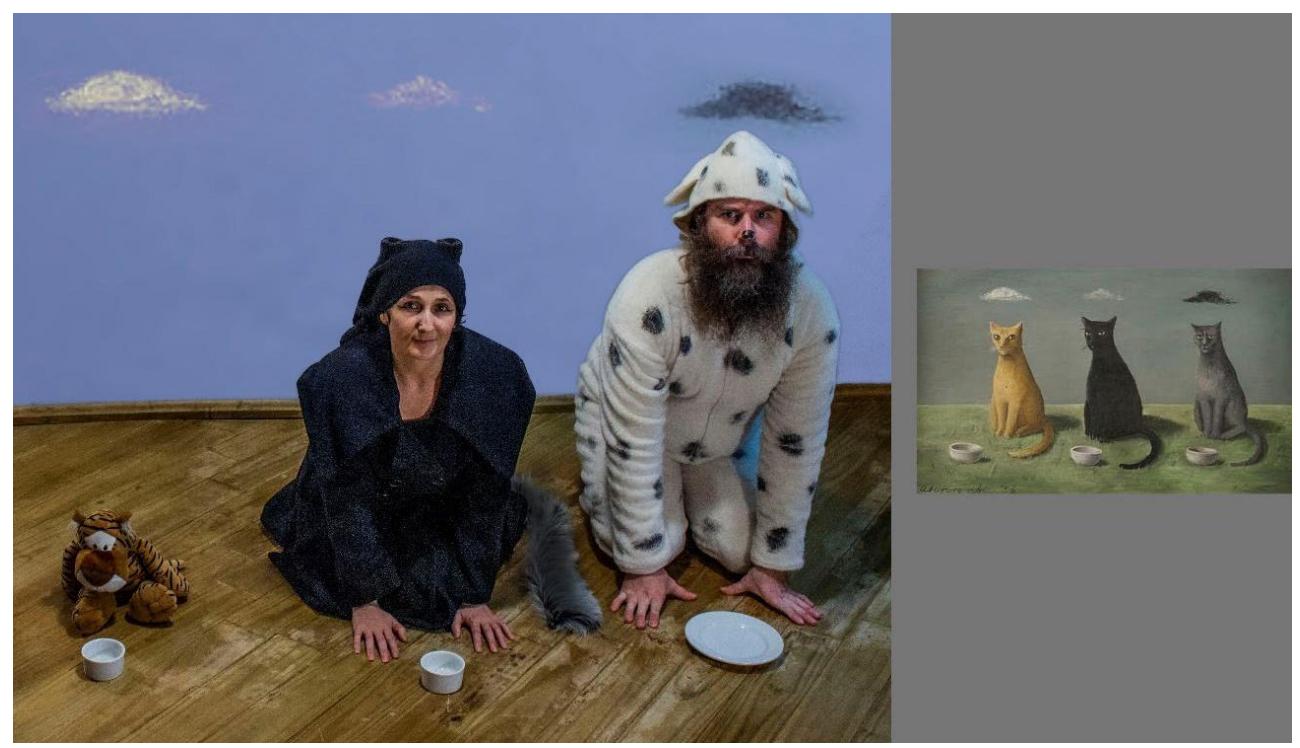

Imagem 11 Releitura de Gertrude Abercrombie - Três gatos (coleção particular). Foto de Thiago Rodeghiero. Fonte: Arquivo Pessoal, 2020 
Fotoperformance como Estratégia Artística: Isolamento Social Voluntário e Reinvenção da Casa

Tatiana dos Santos Duarte • Thiago Heinemann Rodeghiero

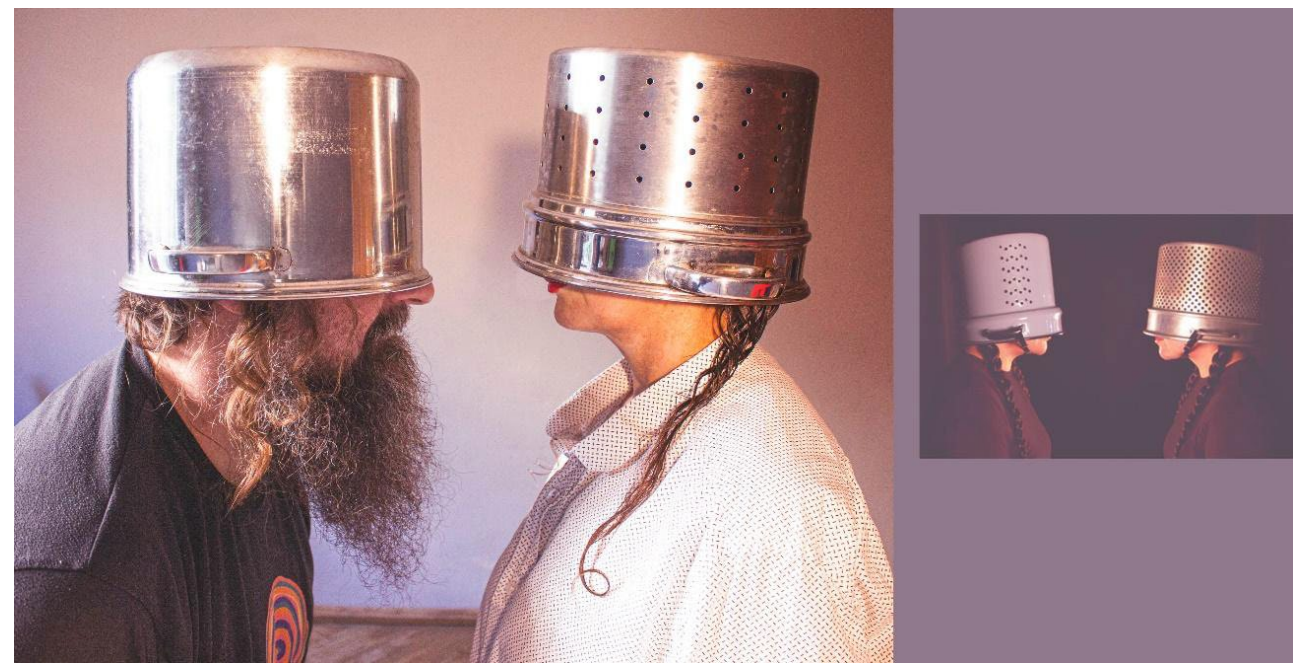

Imagem 12 Releitura de Tania Candiani - Cascos Protetores (Galeria Vermelho). Foto de Thiago Rodeghiero. Fonte: Arquivo Pessoal, 2020.

\section{Referências}

FOUCAUlt, Michel. História da sexualidade 3: O cuidado de sI. Rio de 8 Janeiro/São Paulo: Paz e Terra, 2017.

GIL, José. Movimento total. O corpo e a dança. Lisboa: Relógio D’ Água, 2001.

mbembe, Achille. Necropolítica. 3. ed. São Paulo: n-1 edições, 2018.

VINHOSA, LUCIANO. FotoperformanCE - PASSOS TITUBEANTES DE UMA LINGUAGem em EMAnCiPAÇ̃̃o. In: Anals do $23^{\circ}$ Encontro da ANPAP - "Ecossistemas Artísticos", Belo Horizonte: 2014. (p. 2876 - P. 2885) 